\title{
Vision loss associated with the use and removal of intraocular silicone oil
}

\author{
Patrick D Williams' \\ Christopher G Fuller' \\ Ingrid $U$ Scott ${ }^{2}$ \\ Dwain G Fuller' \\ Harry W Flynn Jr ${ }^{3}$ \\ 'Texas Retina Associates, Dallas, \\ TX, USA; ${ }^{2}$ Departments \\ of Ophthalmology and Health \\ Evaluation Sciences, Penn State \\ College of Medicine, Hershey, PA, \\ USA; ${ }^{3}$ Department of Ophthalmology, \\ Bascom Palmer Eye Institute, \\ University of Miami Miller School \\ of Medicine, Miami, FL, USA
}

Purpose: To describe vision loss associated with the use or removal of silicone oil retinal tamponade.

Methods: Records were reviewed of all patients with a decrease in visual acuity of at least 3 Snellen lines from best acuity with 5000 centistoke silicone oil in place or after removal of silicone oil at a single retina-only practice between 1996 and 2006.

Results: Nine patients (6 men, 3 women) with a mean age of 48 years (range, 16-61) met study inclusion criteria. Seven patients lost at least three Snellen lines of vision while the silicone oil was in place. Four patients had late modest improvements in acuity when compared to their final recorded Snellen vision before silicone oil removal, however no patients exhibited visual improvement when comparing their final recorded visual acuities after oil removal with best recorded acuities under oil tamponade. Loss of the foveal depression was a consistent feature on optical coherence tomography.

Conclusions: Vision loss is a possible complication of silicone oil use and removal. Late visual improvement may occur in some patients. Further research is warranted to elucidate the mechanism(s) of vision loss associated with the use or removal of silicone oil.

Keywords: retinal tamponade, visual acuity, snellen vision, silicone oil

\section{Introduction}

Silicone oil for use during vitreoretinal surgery was first reported in the United States by Paul Cibis in 1962, although almost two decades passed before the agent gained general acceptance among American vitreoretinal surgeons (Cibis et al 1962). The long-lasting retinal tamponade provided by silicone oil is of particular benefit when attempting to repair retinal detachments associated with severe proliferative vitreoretinopathy, diabetic retinopathy, viral retinitis, and ocular trauma (Gallemore and McCuen). Since its introduction, there has been controversy concerning the safety of silicone oil for intraocular use (Cibis et al 1962; Okun 1965; Post 1965; Fuller 1986).

Removal of silicone oil is typically advocated for a number of reasons. Prolonged silicone oil tamponade has been demonstrated to induce anterior segment complications, including cataract, glaucoma, and keratopathy (Chan and Okun 1986). Data obtained from enucleated, glaucomatous eyes suggest that silicone oil droplets can become impregnated within the neuroretina, pigment epithelium, optic nerve, and trabecular meshwork (Honda et al 1986; Shields and Eagle 1989). Finally, removal of silicone oil is commonly associated with improved visual acuity because of the mitigation of refractive errors.

Unexplained loss of vision in eyes following silicone oil removal has recently been described in two reports (Newsom et al 2004; Cazabon et al 2005). Although several possible hypotheses were advanced, neither report provides a conclusion as to the pathophysiology of the vision loss. The current study examines visual loss both during the time of silicone oil tamponade and after oil removal. 


\section{Methods}

Medical records were reviewed of all patients with a documented loss of visual acuity of at least three Snellen lines from best acuity with silicone oil in place or after removal of silicone oil at a single retina practice in Dallas and Arlington, Texas between 1996 and 2006. Data collected include age, gender, involved eye, type of retinal detachment, macular status at the time of surgery, type of surgery performed, duration (in days) of silicone oil fill, and visual acuity during and after silicone oil tamponade. Visual acuity through intraocular oil was recorded using a potential acuity meter. Visual acuity after oil removal was recorded with a Snellen chart. The results of any ancillary testing performed (such as fluoroscein angiography, optical coherence tomography [OCT], and perimetry) were also recorded.

\section{Results}

Nine patients (six men, three women) with a mean age of 48 years (range, 16 to 61 years) met study inclusion criteria. Clinical characteristics of the study population are summarized in Table 1. In seven eyes, perfluorocarbon liquid was used during retinal detachment repair to flatten the retina.
All cases were performed with 5000-centistoke silicone oil. All eyes underwent 360-degree laser retinopexy, and all eyes maintained retinal attachment.

Visual acuity data during and after the period of silicone oil tamponade are presented in Table 2. Seven patients lost at least three Snellen lines of vision while the silicone oil was in place. Four patients had late modest improvements in acuity when compared to their final recorded Snellen vision before silicone oil removal, however no patients exhibited visual improvement when comparing their final recorded visual acuities after oil removal with best recorded acuities under oil tamponade

The average time of silicone oil fill was 469 days (range, 80-3104 days; median 119 days). Patient 8 refused to have oil removal for eight years due to good vision with the oil in place. If the data from patient 8 is excluded as an outlier, a more representative mean of 139 days is derived. The median best recorded visual acuity by potential acuity meter testing with in place was 20/40 at a median of 27 days after oil placement (range, 6-1285 days; mean, 176 days; mean is 37 days if patient 8 is excluded). The median visual acuity by potential acuity meter at the last visit before removal of silicone oil was 20/200 (range, 20/40-20/400). Patients were followed for

Table I Patient and ocular characteristics in study population with visual acuity loss associated with silicone oil use or removal

\begin{tabular}{|c|c|c|c|c|c|c|c|}
\hline Patient nmber & Age & $\begin{array}{l}\text { Reason for } \\
\text { slicone oil }\end{array}$ & $\begin{array}{l}\text { Associated } \\
\text { pathology }\end{array}$ & $\begin{array}{l}\text { Macula detached } \\
\text { preoperatively }\end{array}$ & $\begin{array}{l}\text { Phakic prior } \\
\text { to silicone oil }\end{array}$ & $\begin{array}{l}\text { Cataract } \\
\text { extraction? }\end{array}$ & $\begin{array}{l}\text { Timing of cataract } \\
\text { extraction and } I O L\end{array}$ \\
\hline 1 & 61 & $\begin{array}{l}\text { Multiple } \\
\text { inferior tears }\end{array}$ & & No & Yes & Yes & After SO removal \\
\hline 2 & 51 & $\begin{array}{l}\text { Giant retinal } \\
\text { tear }\end{array}$ & & No & Yes & Yes & After SO removal \\
\hline 3 & 58 & $\begin{array}{l}\text { Inferior } \\
\text { recurrent } \\
\text { RD with PVR }\end{array}$ & & No & Yes & Yes & After SO removal \\
\hline 4 & 16 & $\begin{array}{l}\text { Inferior RD } \\
\text { with multiple } \\
\text { tears }\end{array}$ & $\begin{array}{l}\text { High myopia, } \\
\text { Marfan's } \\
\text { syndrome }\end{array}$ & No & Yes & Yes & With SO removal \\
\hline 5 & 37 & $\begin{array}{l}\text { Recurrent } \\
\text { detachment } \\
\text { with PVR }\end{array}$ & $\begin{array}{l}\text { Optic neuritis, } \\
\text { epiretinal } \\
\text { membrane }\end{array}$ & No & Yes & No & \\
\hline 6 & 57 & $\begin{array}{l}\text { Recurrent } \\
\text { inferior RD }\end{array}$ & High myopia & No & No & & \\
\hline 7 & 52 & $\begin{array}{l}\text { Giant retinal } \\
\text { tear }\end{array}$ & & No & Yes & Yes & After SO removal \\
\hline 8 & 44 & $\begin{array}{l}\text { Recurrent } \\
\text { inferior RD } \\
\text { with PVR }\end{array}$ & High myopia & Yes & No & & \\
\hline 9 & 57 & $\begin{array}{l}\text { Giant retinal } \\
\text { tear }\end{array}$ & & Yes & Yes & Yes & $\begin{array}{l}\text { Extraction with SO } \\
\text { placement, IOL with } \\
\text { SO removal }\end{array}$ \\
\hline
\end{tabular}

Abbreviations: IOL, Intraocular lens; PVR, proliferative vitreoretinopathy; RD, retinal detachment; SO, silicone oil. 
Table 2 Visual acuity (VA) characteristics during and after silicone oil tamponade

\begin{tabular}{llllllll}
\hline Pt \# & $\begin{array}{l}\text { Best VA with oil } \\
\text { (PAM) }\end{array}$ & $\begin{array}{l}\text { Days b/t oil } \\
\text { placement } \\
\text { and best VA }\end{array}$ & $\begin{array}{l}\text { VA at final } \\
\text { exam before oil } \\
\text { removal (PAM) }\end{array}$ & $\begin{array}{l}\text { Total days } \\
\text { with oil }\end{array}$ & $\begin{array}{l}\text { Best VA } \\
\text { after oil } \\
\text { removal }\end{array}$ & $\begin{array}{l}\text { Days between oil } \\
\text { removal and final } \\
\text { recorded VA }\end{array}$ & $\begin{array}{l}\text { Final } \\
\text { recorded VA }\end{array}$ \\
\hline 1 & $20 / 40$ & 27 & $20 / 200$ & 119 & CF & 249 & CF \\
2 & $20 / 50$ & 20 & $20 / 70$ & 80 & $20 / 60$ & 386 & $20 / 60$ \\
3 & $20 / 40$ & 69 & $20 / 200$ & 147 & $20 / 200$ & 496 & $20 / 400$ \\
4 & $20 / 50$ & 20 & $20 / 200$ & 248 & $20 / 100$ & 65 & $20 / 100$ \\
5 & $20 / 40$ & 8 & $20 / 300$ & 96 & $20 / 120$ & 113 & $20 / 120$ \\
6 & $20 / 60$ & 59 & $20 / 400$ & 224 & $20 / 400$ & $12 / 8$ & CF \\
7 & $20 / 40$ & 89 & $20 / 40$ & 111 & $20 / 100$ & 274 & $20 / 100$ \\
8 & $20 / 30$ & 1285 & $20 / 70$ & 3104 & $20 / 40$ & 758 & $20 / 40$ \\
9 & $20 / 25$ & 6 & $20 / 100$ & 88 & $20 / 400$ & 105 & $20 / 400$ \\
\hline
\end{tabular}

an average of 407 days (range, 65-1218 days) after silicone oil removal. The median best recorded visual acuity after oil removal was 20/120 (range, 20/40-count fingers) at a mean of 346 days post removal (range, 54-934 days). Patient 9 had a moderate vitreous hemorrhage on the first postoperative day that resolved spontaneously. The median final recorded visual acuity was 20/120 (range, 20/40-count fingers) at a median of 274 days (range, 65-1218 days; mean, 407 days).

The results of OCTs performed after silicone oil removal are described in Table 4. Patient 8 had a small macular hole diagnosed by OCT 72 days after oil removal. The macular hole resolved spontaneously 10 months later (confirmed by OCT), with improvement in visual acuity from 20/100 to 20/40. Fluorescein angiography was performed on patients
1,2 , and 3 . The angiogram of patient 1 was notable for early punctate staining of the macula consistent with fine drusen, while patients 2 and 3 demonstrated normal angiography. Patient 2 had a normal Goldmann visual field after oil removal and potential acuity meter visual acuity testing ranging from $20 / 100$ to $20 / 300$ before cataract extraction.

At no time did any patients exhibit persistent spikes in intraocular pressures, and the investigators never had tangible reason to suspect that glaucoma played an important etiologic role in any of the aforementioned cases of inexplicable vision loss.

\section{Discussion}

Vision loss associated with silicone oil use and removal is typically severe and permanent. Vision loss may be masked

Table 3 Optical coherence tomography findings after silicone oil removal

\begin{tabular}{|c|c|c|c|}
\hline Patient number & $\begin{array}{l}\text { Time after oil } \\
\text { removal (Days) }\end{array}$ & $\begin{array}{l}\text { Foveal thickness } \\
\text { (microns) }\end{array}$ & Comments \\
\hline I & 11 & 204 & $\begin{array}{l}\text { Decreased foveal } \\
\text { depression }\end{array}$ \\
\hline 2 & 24 & 187 & Normal OCT \\
\hline 3 & 48 & 243 & $\begin{array}{l}\text { No foveal depression, } \\
\text { mild CME }\end{array}$ \\
\hline 4 & 65 & 189 & $\begin{array}{l}\text { Decreased foveal } \\
\text { depression }\end{array}$ \\
\hline 5 & 41 & 248 & $\begin{array}{l}\text { Decreased foveal } \\
\text { depression }\end{array}$ \\
\hline 6 & 1218 & 140 & Thin, myopic fundus \\
\hline 7 & 36 & 209 & $\begin{array}{l}\text { Decreased foveal } \\
\text { depression }\end{array}$ \\
\hline 8 & 72 & $\mathrm{n} / \mathrm{a}$ & Small macular hole \\
\hline 9 & - & - & No OCT performed \\
\hline
\end{tabular}

Abbreviations: CME, cystoid macular edema; OCT, optical coherence tomography. 
Table 4 Potential mechanisms of vision loss associated with the use, or removal, of silicone oil

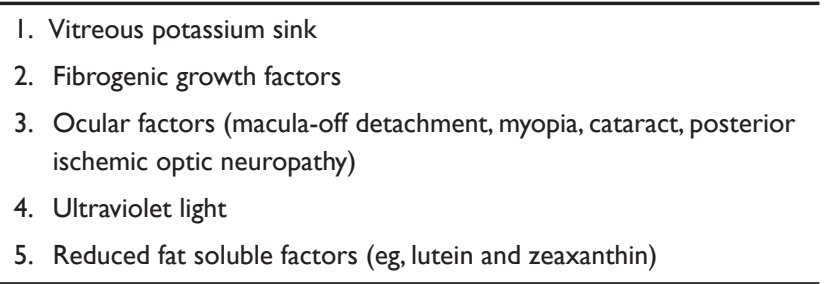

by the fact that many eyes that receive silicone oil tamponade have severe retinal conditions with poor central vision at the time of oil placement. Therefore, their physicians assume the subsequent limited central vision following oil removal is due to pre-existing retinal damage.

In the current study, seven of ten patients had a three Snellen line decrease in visual acuity recorded prior to silicone oil removal. Herbert and colleagues (2006) noted similar findings in a five-patient, retrospective study, documenting the development of subjective central scotomas in advance of oil removal. The oil was in place for an average of 2.7 months when the scotomas arose and were associated with decreased visual acuity and visual field defects.
Various theories have been offered to explain the vision loss associated with the use, or removal, of silicone oil tamponade (Table 5). According to the "vitreous potassium sink" theory, the vitreous cavity in a normal eye provides a reservoir for the release of potassium ions by Müller cells, thereby buffering intraretinal potassium spikes (Winter et al 2000). This theory was first presented as an explanation for perfluorocarbon liquid toxicity. It is hypothesized that the aqueous volume between the perfluorocarbon and the retina is far too small to serve as a sufficient sink for the siphoning of potassium ions and that elevated retinal potassium concentration could trigger apoptosis and macular dysfunction. Cazabon and colleagues (2005) proposed the same mechanism as an explanation for vision loss associated with silicone oil removal. Figure 1 demonstrates the existence of a oil-fluid interface over the foveal depression in a patient without unexpected vision loss. The rapid disruption in electrolyte concentration in the "potassium sink" may explain the sudden vision loss with silicone oil removal. Based on pattern electroretinogram and multifocal electrogram testing, Cazabon and colleagues (2005) localized the damage to the outer retinal layers of the central macula.

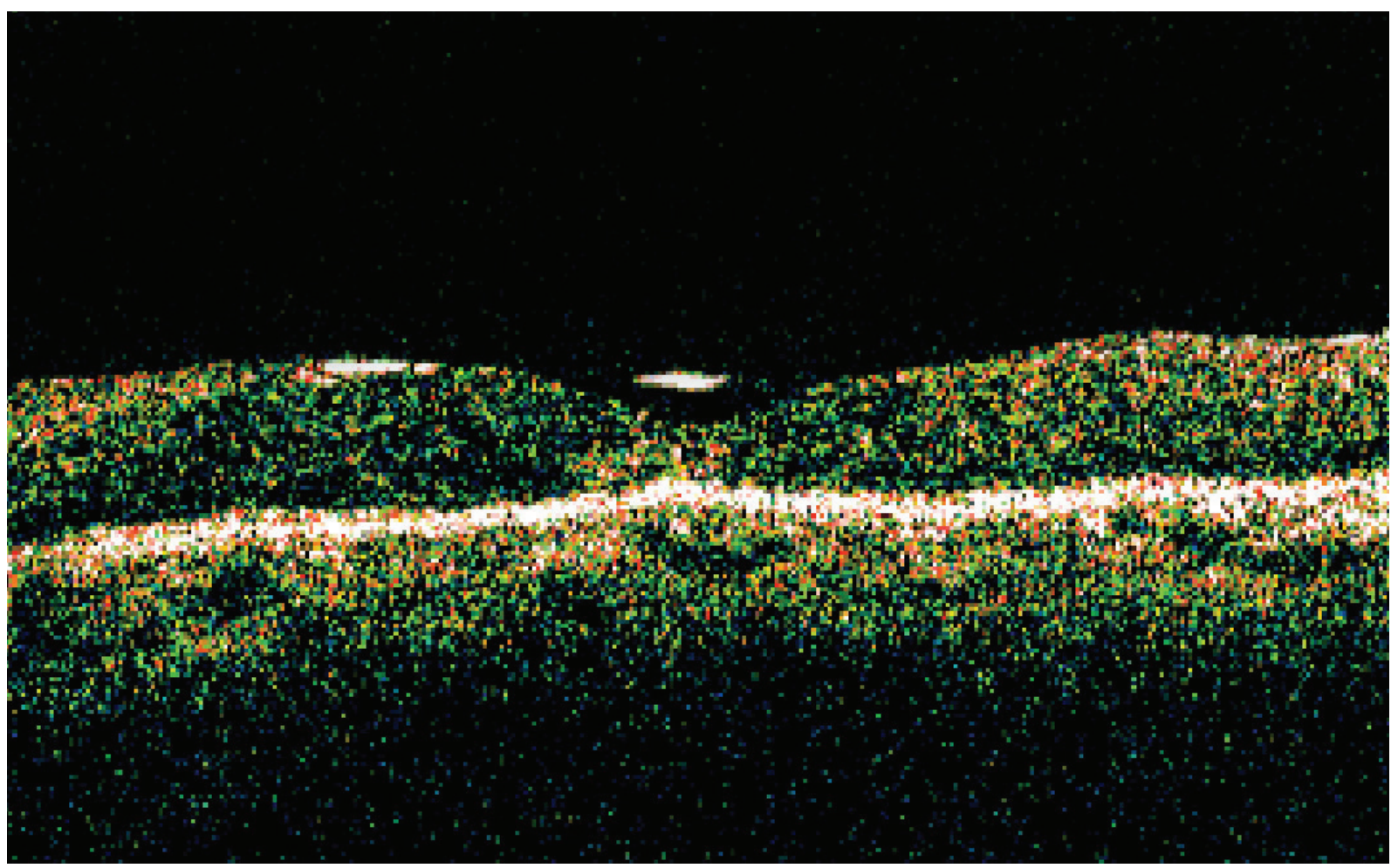

Figure I Optical coherence tomography image of silicone oil-fluid interface over the foveal depression in a patient without associated vision loss. 
The sporadically noted optic neuropathy following silicone oil removal has led to the hypothesis that a similar "sink" might exist within the optic cup (Satchi et al 2005). Based on OCT, an interface similar to that presented in Figure 1 exists over the optic cup. Another author, citing afferent pupillary defects in a handful of patients, points to posterior ischemic optic neuropathy as playing a possible causative role (Tavallali and Soheilian 2005). This was deemed unlikely by Newsom and colleagues given their patients' relative youth, excellent vascular health, and, in 6 of 7 patients, preserved visual evoked potentials (Newsom et al 2005).

One group of investigators has documented increased concentrations of fibrogenic growth factors (notably basic fibroblast growth factor and interleukin-6) in the retro-oil fluid (Asaria et al 2004), although this would likely contribute more to perisilicone proliferation than unexplained vision loss following removal of silicone oil. No such perisilicone membranes were documented in these patients.

Silicone oil transmits certain frequencies of ultraviolet light more readily than the vitreous gel, and aphakic patients might be particularly susceptible to phototoxic damage (Azzolini et al 1992). Moreover, silicone oil is believed to dissolve fat soluble elements from the retina, most notably lutein and zeaxanthin, both of which are widely thought to serve photo-protective roles (Refojo et al 1998; Herbert et al 2005).

The exact etiology of vision loss in the current study group is unknown. Confounding variables such as cataract surgery, high myopia, and macular detachment must be considered in some patients. Four of eight patients in this study had a decrease in the foveal depression on OCT (OCTs were not routinely performed, and were only utilized when the clinician could not ascertain another viable reason for poor visual function in the absence of obvious architectural abnormalities). The significance of this finding is unclear, but it could suggest a maculopathy with architectural foveal changes. Based on the "potassium sink" theory, the OCT changes could represent anatomic changes secondary to a localized foveal toxicity. Another possibility is simply poor fixation due to poor vision.

\section{Conclusion}

The use of silicone oil is an important management tool for many complex retinal conditions. Future studies are warranted to evaluate the risk of unanticipated central visual loss.

\section{Disclosure}

The authors report no conflicts of interest in this work.

\section{References}

Asaria R, Kon C, Sethi C, et al. 2004. Silicone oil concentrates fibrogenic growth factors in the retro-oil fluid. Br J Ophthalmol, 88:1439-42.

Azzolini C, Docchio F, Brancato R, et al. 1992. Interactions between light and vitreous fluid substitutes. Arch Ophthalmol, 110:1468-71.

Cazabon S, Groenewald C, Pearce I, et al. 2005. Visual loss following removal of intraocular silicone oil. Br J Ophthalmol, 89:799-802.

Chan C and Okun E. 1986. The question of ocular tolerance to intravitreal liquid silicone: a long-term analysis. Ophthalmology, 93:651-9.

Cibis P, Becker B, Okun E, et al. 1962. The use of liquid silicone in retinal detachment surgery. Arch Ophthalmol, 68:590-9.

Fuller D. 1986. The question of ocular tolerance to intravitreal liquid silicone. Ophthalmology, 93:659-60.

Gallemore R and McCuen B. Silicone oil in vitreoretinal surgery. In: Ryan SJ, (editor). Retina. St. Louis, MO: Mosby, Inc; pp. 2212-34.

Herbert E, Liew S, Williamson T, et al. 2005.Visual loss after silicone oil removal. Correspondence. Br J Ophthalmol, 12:1667-8.

Herbert E, Habib M, Steel D, et al. 2006. Central scotoma associated with intraocular silicone oil tamponade develops before oil removal. Graefe's Arch Clinical Exp Ophthalmol, 244:248-52.

Honda Y, Ueno S, Miura M, et al. 1986. Silicone oil particles trapped in the subretinal space: complications after substitution of the vitreous. Ophthalmologica, 192:1-5.

Newsom S, Johnston R, Sullivan P, et al. 2004. Sudden visual loss after removal of silicone oil. Retina, 24:871-7.

Newsom S, Johnston R, Sullivan P, et al. 2005. Reply. Retina, 25:806-7.

Okun E. 1965. Paul Anton Cibis (1911-1965). Am J Ophthalmol, 60:546-8.

Post M. 1965. Paul Anton Cibis M.D. Trans Am Oph Soc, 63:8-10.

Refojo MF, Leong FL, Chung H, et al. 1998. Extraction of retinol and cholesterol by intraocular silicone oils. Ophthalmology, 95:614-8.

Satchi K, Bolton A, Patel CK, et al. 2005. Correspondence. Retina, 25:807-8.

Shields C and Eagle R. 1989. Pseudo-Schnabel's cavernous degeneration of the optic nerve secondary to intraocular silicone oil. Arch Ophthalmol, 107:714-7.

Tavallali A and Soheilian M. 2005. Correspondence. Retina, 25:806.

Winter M, Eberhardt W, Scholz C, Reichenbach A, et al. 2000. Failure of potassium siphoning by Müller cells: a new hypothesis of perfluorocarbon liquid-induced retinopathy. Invest Ophthalmol Vis Sci, 41:256-60. 
